\title{
MOVIMENTOS SOCIAIS: CONSTRUINDO ALTERNATIVAS PARA SUPERAR OS LIMITES DA DEMOCRACIA REPRESENTATIVA
}

\author{
SOCIAL MOVEMENTS: FORMULATING ALTERNATIVES TO \\ OVERCOME THE LIMITS OF REPRESENTATIVE DEMOCRACY
}

\section{MOVIMIENTOS SOCIALES: CONSTRUYENDO ALTERNATIVAS PARA SUPERAR LOS LÍMITES DE LA DEMOCRACIA REPRESENTATIVA}

Licença CC BY: Artigo distribuído sob os termos Creative Commons, permite uso e distribuição irrestrita em qualquer meio desde que o autor credite a fonte original.

\section{(c) (i)}

\section{Clovis Gorczevski ${ }^{1}$ Denise Bittencourt Friderich²}

Resumo: Indagou-se o seguinte: a abertura de espaços e instrumentos de escuta e efetiva participação dos movimentos sociais é uma possibilidade de superação dos limites da democracia representativa? Objetivou-se investigar a democracia representativa, descrevendo-a e apontando seus limites. Também se investigaram os movimentos sociais e as suas potencialidades para sanar os deficits de legitimidade da democracia representativa. Para a construção da pesquisa, utilizou-se o método de abordagem indutivo, na medida em que, da investigação dos limites da democracia representativa e das possibilidades emancipatórias dos movimentos sociais, construiu-se um modelo democrático condizente com a necessidade de acomodação de interesses que brotam na sociedade plural da atualidade. O procedimento será o bibliográfico. Conclui-se que os movimentos sociais representam o pluralismo cultural das sociedades complexas e atuam em favor da democracia implantada no pós-Segunda Guerra. Um Estado comprometido com tais valores está obrigado a fomentar e recepcionar as demandas oriundas dos movimentos sociais.

Palavras-chave: Democracia representativa; movimentos sociais.

$1 \quad$ Advogado, doutor em Direito (Universidad de Burgos, 2001), pós-doutor em Direito (CAPES - Universidad de Sevilla, 2007); (CAPES - Fundación Carolina - Universidad de La Laguna, 2010). Professor permanente do PPGD da Universidade de Santa Cruz do Sul. Rio grande do Sul. Brasil. E-mail: clovisg@unisc.br.

2 Doutora em Direito pela Universidade de Santa Cruz do Sul. Professor permanente do PPGD da Universidade de Santa Cruz do Sul. Rio Grande do Sul. Brasil. E-mail: dfriedrich@unisc.br. 


\begin{abstract}
The following question was asked: does the opening of spaces and instruments for listening and effective participation of social movements provide an opportunity to overcome the limits of representative democracy? The aim of this study was to investigate representative democracy, describing it and pointing out its limits. Social movements and their potentialities were also investigated, seeking to remedy the legitimacy deficits of representative democracy. For the construction of the research, the inductive approach was used, since, from the investigation of the limits of the representative democracy and the emancipatory possibilities of the social movements, a democratic model was built in agreement with the need to accommodate the interests that arise in today's plural society. The procedure used is bibliographic. It is concluded that social movements represent the cultural pluralism of complex societies, and act in favor of the democracy introduced after the Second World War. A State that is committed to such values is bound to foster and welcome the demands of social movements.
\end{abstract}

Keywords: Representative democracy; social movements.

Resumen: Se investigo sobre lo siguiente: ટla apertura de espacios e instrumentos de escucha y efectiva participación de los movimientos sociales es una posibilidad de superación de los límites de la democracia representativa? Se objetivó investigar la democracia representativa, describiéndola y apuntando sus límites. También se investigaron los movimientos sociales y sus potencialidades para sanar los deficits de legitimidad de la democracia representativa. Para la construcción de la investigación, se utilizó el método de abordaje inductivo, en la medida en que, de la investigación de los límites de la democracia representativa y de las posibilidades emancipatorias de los movimientos sociales, se construyó un modelo democrático condecente con la necesidad de acomodación de interés que brotan en la sociedad plural de la actualidad. El procedimiento será el bibliográfico. Se concluyó que los movimientos sociales representan el pluralismo cultural de las sociedades complejas y actúan en favor de la democracia implantada en la posguerra de la Segunda Guerra Mundial. Un Estado comprometido con tales valores está obligado a fomentar y recepcionar las demandas oriundas de los movimientos sociales.

Palabras-clave: Democracia representativa; movimientos sociales. 
Não sem razão, a segunda Grande Guerra é indicada como um divisor de águas entre o constitucionalismo moderno e o constitucionalismo contemporâneo, agregando à expressão Estado de Direito o ideal democrático. Naquele momento histórico, pareceu não ser suficiente que as instituições estatais submetessem apenas ao direito, mas que fossem, todas elas, pensadas a partir da participação dos seus cidadãos, os verdadeiros detentores do poder, que poderiam exercê-lo de forma direita ou mediante a escolha de representantes. Surge assim o Estado Democrático de Direito no seio de um movimento constitucional, que, se não é totalmente novo, apresenta-se remodelado a tal ponto de alguns o denominarem de novo (ou neo) constitucionalismo.

Em tal modelo constitucional a dignidade da pessoa humana é colocada como princípio matriz e a própria sociedade civil reivindica maiores espaços de participação e deliberação para assegurar decisões políticas garantidoras da própria dignidade e dos interesses da diversidade e da pluralidade que se acentua. A fim de assegurar esses valores, materializam-se nos textos constitucionais conteúdos que antes não figuravam, conteúdos que vão além da mera ordenação do Estado, alcançando temas de cunho axiológicos dependentes de uma atividade interpretativa extensa para, diante da incalculável casuística, dizer o direito. É assim que o Poder Judiciário se apresenta como o órgão que, em última instância, interpreta as cartas constitucionais, com um protagonismo nunca visto.

Por certo que esse novo paradigma reflete na operacionalização do Direito e do Estado, demandando uma nova perspectiva de análise dos arranjos democráticos e do debate acadêmico, especialmente por três razões: (1) porque a relação entre os poderes do Estado demanda acomodações frente à demanda pela concretização dos direitos fundamentais; (2) porque é neste momento histórico que nascem os Estados Democráticos de Direito, no qual o direito de participação é visto como forma de assegurar a autonomia social e individual (e isso reflete nos espaços de tomada de decisão política aberta à sociedade), tornase princípio constitucional, e (3) em tal contexto o pluralismo ocupa lugar nos debates jurídicos constitucionais, nascendo, com isso, a dificuldade de atender 
a imensurável diversidade de interesses a serem contempladas nas decisões exigidas do Estado.

Mas, dentre várias características desse movimento constitucional, para o presente artigo importa o fato de ter ele se erigido sobre o pilar da democracia e dos direitos fundamentais. Tais pilares nem sempre possuem uma relação harmônica, pelo contrário, constantemente são acusados de um antagonismo difícil ou impossível de ser superado. Para os que defendem o conflito entre democracia e direitos fundamentais, não há maneira aceitável de conciliar a vontade da maioria (representada pelo princípio democrático) com as liberdades individuais (representadas pelos direitos fundamentais). Em outras palavras, como lidar com a dicotomia democracia e direitos fundamentais? Porém, cabe advertir que o paradoxo se deve em razão de uma visão meramente representativa da democracia, na qual os cidadãos exercem sua soberania ao elegerem seus representantes e, em regra pelo sistema majoritário, segundo o qual a maioria decide. Em sistemas democráticos representativos majoritários, com muita facilidade, uma ditadura da maioria pode se instaurar.

O presente trabalho defende que a democracia requisitada pelo constitucionalismo contemporâneo exige outros instrumentos de exercício do poder cujo titular é o povo. Desse diagnóstico, vários instrumentos de participação direta e mais efetiva vêm sendo construídos, tais como o plebiscito e o referendo. Porém, neste trabalho abre-se espaço para se discutir outras ferramentas de superação dos limites da democracia representativa. Daí o questionamento que a presente pesquisa visa sanar: a abertura de espaços e instrumentos de escuta e efetiva participação dos movimentos sociais é uma possibilidade de superação dos limites da democracia representativa? A provável resposta para a indagação é que sim, ou seja, criar espaços efetivos para que os movimentos sociais, que representam o pluralismo cultural de uma dada sociedade, é uma maneira muito rica e alinhada aos ideais democráticos inaugurados pelo constitucionalismo contemporâneo. Por esta razão, um Estado comprometido com tais valores está obrigado a criar a fomentar e recepcionar as demandas oriundas dos movimentos sociais.

O caminho trilhado para construir a resposta para a indagação anteriormente 
descrita será o indutivo, na medida em que, da investigação dos limites da democracia representativa e das possibilidades emancipatórias dos movimentos sociais, construir-se-á um modelo democrático condizente com a necessidade de acomodação de interesses que brotam na sociedade plural da atualidade. $O$ procedimento será o bibliográfico.

Primeiramente, dedicar-se-á à democracia representativa, descrevendo-a e apontando seus limites. Em seguida, o objeto de análise serão os movimentos sociais e as suas potencialidades para sanar os deficits de legitimidade da democracia representativa.

\section{Entre a cruz e a espada: a democracia representativa como possibilidade e os limites de legitimidade para as decisões políticas}

A democracia representativa, quando o tema é o pluralismo cultural, apresenta-se um tanto quanto paradoxal, porque ao mesmo tempo que ela é pensada exatamente porque se tem uma pluralidade de vontades e interesses, já que se houvesse a uniformidade desses não haveria conflito de interesses e as decisões políticas seriam fáceis na medida em que o próprio representante seria o retrato da sociedade que representa. Por outro lado, é a diversidade cultural que faz acentuar os deficits de legitimidade do modelo representativo, pois, de forma geral, utilizam do critério majoritário para legitimarem suas decisões.

Desta relação paradoxal, quer-se dar especial atenção para o segundo problema levantado, ou seja, como assegurar a legitimidade das decisões, frente às minorias, se apenas a vontade da maioria foi levada em conta para o produto final da decisão. Esse problema não é novo, Alex de Toqueville ${ }^{3}$ o descreveu de forma detalhada ao investigar a democracia nos Estados Unidos, advertindo para os perigos de termos uma tirania da maioria. $O$ então juiz francês, que fora aos Estados Unidos da América estudar o sistema penitenciário, acabou dedicando-se ao estudo do modelo democrático americano. O autor observou uma série de falhas que deram margem para um governo demagogo, de pessoas desqualificadas e manipuladoras que convenciam as multidões sem que estas percebessem a manipulação que se sujeitavam. ${ }^{4}$

3 TOCQUEVILLE, Alexis. A democracia na América: lei e costumes. Tradução de Eduardo Brandão. $2^{\mathrm{a} e d .}$ São Paulo: Martins Fontes, 2005.

4 De certa forma, Tocqueville retoma a ideia de Aristóteles sobre a democracia, segundo a qual ela é uma forma deturpada e corrompida de governo, que se contrapõe ao modelo republicano. Para Aristóteles (2001), as três 
Crítica semelhante faz John Dewey, citado por Jack Knight ${ }^{5}$, ao observar que, por si mesma, a regra da maioria para fundamentar decisões políticas absurdas. Segundo ele, o remédio não é simplesmente expandir, ou mesmo refinar a democracia agregativa, mas, ao contrário, recorrer a uma deliberação democrática maior e melhor, por meio do aperfeiçoamento das condições de debate, discussão e persuasão.

Interessante que dentre as teorias clássicas ${ }^{6}$ que tratam da democracia, o modelo liberal é o que rechaça e valida a representatividade. Primeiro rechaça, pelo fato de defender que o princípio majoritário não deve invadir as esferas de escolhas individuais que só cabem ao próprio individuo; em segundo valida, mas como forma de eleger seus representantes; mas para proteger seu valor maior que é a liberdade individual, concebe a própria natureza do Estado de forma limitada, sem que este contenha demasiados poderes, para evitar os riscos de abusos. Dizendo de outra forma: para os defensores da democracia liberal, a representatividade só é concebível se quem for eleito como representante tiver poderes bastante restritos para assim evitar que a vontade da maioria suplante os interesses minoritários.

Mill7 justifica o modelo liberal de democracia pelo fato de ter ocorrido a grande expansão democrática e, logo, a necessidade de criar um sistema possibilitador de voz para um número igualmente grande cidadãos e, com isso, fazer do povo senhor de si mesmo por meio do voto em representantes. Porém, entende ele que a democracia não se mostrou suficiente para proteger o cidadão da tirania do Estado. Ele questiona os limites de atuação da sociedade sobre o indivíduo, ou seja, a opressão da maioria pela minoria é um risco presente nas democracias, mas sustenta um método para evitar este risco: combinar democracia e liberalismo. Chegando a um extremo de defesa da liberdade de

formas de governo defendidas por ele podem degenerar, da seguinte forma: a monarquia em tirania; a aristocracia em oligarquia; a república em democracia. Assim, a tirania não é, de fato, senão a monarquia voltada para a utilidade do monarca; a oligarquia, volta-se para a utilidade dos ricos; e a democracia, dirige-se para a utilidade dos pobres. No sentido atribuído pelo autor, nenhuma das três se ocupa do interesse público. Defende a aristocracia, pois, segundo ele, consiste principalmente em atribuir os cargos mais altos segundo o mérito, portanto, a virtude é a sua principal razão de ser; assim como a riqueza é da oligarquia; e a liberdade é da democracia. Luis. MELO, Rúrion Soares. A democracia deliberativa. São Paulo: Editora Singular, Esfera Pública, 2007.

7 MILL, John Stuart. Sobre la liberdad. Tradução de N. R. Salmones. Madrid: Alianza, 1986. 
escolha individual, Mill leciona que mesmo sob o argumento de garantir o bem do próprio indivíduo não se pode permitir que o Estado interfira, pois sobre seu próprio corpo este tem total poder, de forma que, se o indivíduo quiser fazer mal a si mesmo, desde que não prejudique outros, ele não poderá ser impedido. ${ }^{8}$

De forma geral, acredita que o modelo liberal favorece a própria democracia na proporção em que restringe o âmbito de ação do governo à esfera pública, permitindo com isso que os cidadãos desenvolvam capacidades importantes para o autogoverno, e assim se torne senhores de suas vidas com pouca dependência do Estado. Na democracia liberal, o indivíduo aparece como centro de preocupação, e o que leva as pessoas a participarem (direta ou indiretamente) é a preocupação em fazer o Estado respeitar este âmbito de autonomia individual e assegurar que o exercício da liberdade individual não interfira na liberdade alheia. Desta forma, vê na autonomia individual um valor supremo, por isso a regra de ouro é a não interferência do Estado no âmbito de sua autodeterminação. A dificuldade deste ideal é que nas sociedades contemporâneas as relações intersubjetivas estão muito intensificadas, ficando difícil traçar a linha divisória dos assuntos e dos interesses exclusivamente individuais. Para assegurar esta liberdade, o sistema democrático tem que institucionalizar meios que garantam direitos e liberdades individuais (Direitos fundamentais de primeira dimensão) que são verdadeiras barreiras para a vontade da maioria, ou seja, trunfos que, segundo Novais ${ }^{9}$, "ter um direito fundamental é ter um trunfo contra o Estado, contra o governo democraticamente legitimado". Revela assim a tensão entre Estado de Direito (que recepciona os direitos fundamentais) e democracia (que está assentada na vontade da maioria). Novias (2006) não acredita nesta sintonia entre Estado de Direito e democracia, pelo contrário, afirma existir uma tensão "ineliminável" entre ambos, e aponta os seguintes fatos: a) a maioria no poder pode ameaçar os direitos fundamentais, mesmo que esta maioria seja legitimamente eleita (as atrocidades da Segunda Guerra comprovaram isto), pois procedimentos democráticos não garantem uma identidade natural entre lei e justiça; b) a força de resistência dos direitos fundamentais pode inibir o exercício do poder democrático, especialmente diante de um poder judicial (poder contra

8 "Sobre sí mismo, sobre su cuerpo y su espíritu, el individuo es soberano" (MILL, 1986, p. 27)

9 NOVAIS, Jorge Reis Novais. Direitos fundamentais: trunfos contra a maioria. Coimbra: Coimbra Editora, 2006. p. 17 
majoritário); c) ainda que a prevalência entre direitos fundamentais sobre o principio democrático não seja tão nítida, o legislador acaba sofrendo limites em decorrência do Estado de Direitos. Estes fatos revelam por que Novais acredita na tensão insuperável entre os dois princípios: democracia e Estado de Direito.

Ao tratar do conceito de democracia, Schumpeter ${ }^{10}$ rejeita o conceito tradicional, segundo o qual democracia é o governo do povo. Segundo ele, desta definição decorre, pelo menos, dois problemas: (1) definir quem é o povo e (2) de que forma ele governa. Por isso entende ser melhor substituir esse conceito pela ideia de um governo aprovado pelo povo. Igualmente critica a ideia de bem comum por não ter como chegar de forma segura a esta máxima, já que para diferentes indivíduos e grupos, o bem comum provavelmente significará coisas muito diversas.

Além disso, Schumpeter (1961) aponta a força da mídia sobre as massas, então, mesmo que se chegasse a um acordo unânime do que é bem comum, possivelmente os cidadãos não teriam formado suas convicções livremente, já que tais grupos podem modelar e, dentro de limites muito largos, até mesmo criar a vontade do povo, por isso as escolhas das massas sempre terá sofrido algum tipo de influência que os faz acreditar que estavam decidindo o melhor para a coletividade, sem que de fato pudessem identificar das forças escusas e manipuladoras que agem sobre sua formação de opinião. Daí porque dos processos políticos, por conseguinte, tem-se não uma vontade genuína, mas artificialmente fabricada.

Finalmente, para Schumpeter ${ }^{11}$, a definição de democracia como governo do povo que percorre o bem comum é falha porque muitos fatores influenciam as ações e as escolhas dos cidadãos, como, por exemplo, quando estão sob a influência da aglomeração, fazendo desaparecer os freios morais e maneiras civilizadas de pensamento e sentimento, e emergindo impulsos primitivos, infantilismo e tendências criminais. O produto final da análise do autor gera um senso de responsabilidade reduzido e a ausência de vontade efetiva, por outro lado, explicam a ignorância do cidadão comum: e a falta de bom senso em

10 SCHUMPETER, Joseph A. Capitalismo, socialismo e democracia. Trad. por Ruy Jungmann. Rio de Janeiro: Editora Fundo de Cultura, 1961.

11 SCHUMPETER, Joseph A. Capitalismo, socialismo e democracia. Trad. por Ruy Jungmann. Rio de Janeiro: Editora Fundo de Cultura, 1961. 
assuntos de política interna e externa.

Diante da percepção negativa que Schumpeter ${ }^{12}$ tem do "povo", para ele o seu papel não é de governar, mas simplesmente de formar um governo, e este terá autonomia para fazer as escolhas políticas. Com isso, pode-se verificar que o povo, no modelo competitivo do autor, não decide, tão somente escolhe quem decide por ele. O método democrático é um sistema institucional, para a tomada de decisões políticas, no qual o indivíduo adquire o poder de decidir mediante uma luta competitiva pelos votos do eleitor, à semelhança do que ocorre na disputa pela preferência do consumidor.

Como se pode notar, na percepção dos defensores do modelo liberal de democracia, o papel dos cidadãos deve ser bastante limitado, seja pelas características da natureza humana, seja pelas formas sublimes de manipulação da formação de opinião que se sujeita, seja pela complexidade das sociedades atuais. Em certa medida, concorda-se com os fatos até aqui apontados, porém discorda-se desses teóricos na medida em que não conseguem perceber que a democracia não se restringe ao modelo representativo e que há outras formas de influenciar o processo de tomada de decisão dos quais resultam benefícios de cunho coletivo e individuais. Neste sentido, para a democracia procedimental deliberativa, conjuga a necessidade de manter-se a autonomia individual e a autonomia pública em harmonia, de forma que seus postulados oferecem um procedimento que permite à sociedade revisar, a qualquer momento, seus valores morais consolidados a partir de momentos históricos.

O debate público é valioso porque ajuda os participantes a aprender as razões de suas divergências e distinguir entre assuntos sobre os quais eles podem concordar daqueles em que não é possível alcançar acordo, e isto é fundamental para que os níveis de consciência e participação aumentem no âmbito das relações sociais e de poder.

Segundo Bohman ${ }^{13}$, por meio do diálogo, os sujeitos, livres e iguais, conseguem alcançar um consenso não coercitivo, por meio do qual se aperfeiçoa

12 SCHUMPETER, Joseph A. Capitalismo, socialismo e democracia. Trad. por Ruy Jungmann. Rio de Janeiro: Editora Fundo de Cultura, 1961.

13 BOHMAN, James. O que é a deliberação pública? Uma abordagem dialógica. In: MARQUES, Ângela Cristina Salgueiro. A deliberação pública e suas dimensões sociais políticas e comunicativas: textos fundamentais. Belo Horizonte: Autêntica Editora, 2009, p. 35. 
a "qualidade epistêmica das justificações para decisões políticas". Embora o consenso seja um valor muito caro aos procedimentalistas, para Martí1 ${ }^{14}$, alcançar o consenso não é a razão de ser da deliberação, até porque ela se dirige às decisões políticas, e a política é essencialmente uma questão de conflito ${ }^{15} \mathrm{e}$ poder. Conhecer os limites da deliberação ideal serve como um fato objetivo a ser sopesado nos desenhos institucionais, e não simplesmente rechaçá-la. Logo, a grande vantagem da deliberação não ser um método para atingir o consenso, mas sim o fato de aceitar o pluralismo e permitir aos cidadãos mostrarem um alto grau de respeito mútuo, civilidade e reciprocidade. Sob este enfoque, para Bellamy ${ }^{16}$ o risco de divergência é real e permanecerá enquanto a democracia for vista como extensão da autonomia individual, pois sob esta perspectiva, é impossível conjugar os divergentes pontos de vista. O autor oferece outro enfoque, que vê na democracia deliberativa uma forma de garantir a não dominação.

Seja qual for a vertente filosófica adotada, é certo que nenhuma delas consegue, por si só, dar conta da complexidade das sociedades atuais. Bobbio ${ }^{17}$ descreve as promessas não cumpridas de democracia, dentre as quais indica o cenário em que a democracia nasceu marcada pela ideal contratualista em sociedade individualista, cujas relações sociais são analisadas a partir do sujeito individual que persegue apenas o próprio interesse, sem qualquer preocupação como os demais. Enquadram-se aqui as teorias utilitaristas de Mill e Schumpeter anteriormente descritas. Diante da descrição do nascimento do ideal democrático, o autor identifica um distanciamento entre o contexto teórico, no qual se construíram as teorias democráticas e o contexto real, cujas teorias deveriam ser testadas.

Outra promessa não cumprida, e talvez a mais grave de todas, deve-se ao fato de a democracia não conseguir entrar em todos os espaços de influência das decisões políticas, pois há espaços dominados por poderes que não se abrem à

$14 \quad$ MARTí, José Luis. La república deliberativa: una teoria de la democracia. Madrid: Marcial Pons, 2006.

15 Conforme as contribuições de Mouffe, as buscas pelo consenso é um ponto falho de Habermas que norteia toda sua teoria no propósito de, através da deliberação guiada pelo procedimento, chegar-se ao consenso.

16 BELLAMY, Richard. Republicanism, democracy, and constitutionalism. In: C. Laborde and J. Maynor, eds., Blackwell, 2008, p. 159-189. Disponível em: < http://papers.ssrn.com/sol3/papers. cfm?abstract_id=1520386>. Acessado em 11 jul. 2014. p. 163.0 autor discorda da possibilidade de que possa haver um diálogo em condições ideais, diferentemente de Martí que acredita que a racionalidade dos argumentos depende de condições ideais de argumentação.

17 BOBBIO, Norberto. O futuro da democracia. Tradução de Marco Aurélio Nogueira. 11 ed. São Paulo: Paz e Terra, 2000. 
participação social. Porém, e aqui está sua maior perversidade, são espaços cujas decisões extremamente relevantes para a coletividade são tomadas sem que esta possa participar efetivamente. Com isso todo o ideal de autonomia individual e coletiva, bem como de legitimidade, cai por terra. Contribuindo para esta reflexão, é a obra de Dowbor ${ }^{18}$ que identifica como o Estado democratizou-se, mas que suas decisões não são democráticas na medida em que sofrem fortes influências do setor privado, especialmente dos grandes grupos econômicos, que longe estão de serem democratizados. Pelo contrário, são espaços norteados pelos interesses privados, que buscam o lucro, sem olhar para o coletivo e o bemestar social. ${ }^{19} \mathrm{Em}$ ambientes poucos democráticos, mas altamente irradiadores de respostas aos problemas sociais, o autoritarismo assume novas feições que dificultam identificá-lo e o dissimulam.

Bobbio aponta ainda a falta de educação do cidadão para a democracia. A educação para a democracia surge na própria prática democrática, pois, com ela, se promove, se alimenta e se reforça a própria democracia. Os modelos democráticos desenhados na modernidade contavam com um cidadão virtuoso, comprometido com a gestão do Estado, fato que não se confirmou.

Nos dois últimos parágrafos, retiram-se duas justificativas importantes para o fomento aos espaços de escuta dos movimentos sociais diante de seu potencial legitimador das decisões de ordem social: primeiro, porque tais movimentos representam a sociedade viva com toda a sua riqueza e diversidade, que é capaz de fazer frente ao imperialismo econômico; segundo, porque a educação democrática se adquire a partir da prática em processos democráticos, e os movimentos sociais oportunizam essas práticas.

Um último argumento contra a predominância da representação no cenário democrático refere-se aos altos índices de abstenções, de votos brancos e nulo. No Brasil, nas eleições de 2014 para os cargos do executivo federal (Presidente da República), o Tribunal Superior Eleitoral (TSE) ${ }^{20}$ apurou que, no segundo turno, a chapa composta por Dilma Rousseff e Michel Temer recebeu 54.501.118 votos

18 DOWBOR, Ladislau. Democracia econômica: alternativas de gestão social. Petrópolis: Vozes, 2008.

19 Tais ideias são retomadas pelo mesmo autor em 2017 na obra O Capital Improdutivo.

20 BRASIL, Tribunal Superior Eleitoral Disponível em:< http://www.tse.jus.br/imprensa/noticias-tse/2014/Dezembro/ plenario-do-tse-proclama-resultado-definitivo-do-segundo-turno-da-eleicao-presidencial>. Acesso em: 22 maio 2018. 
Novos Estudos Jurídicos

(51,64\% dos votos válidos) e a chapa integrada por Aécio Neves e Aloysio Nunes Ferreira obteve 51.041 .155 votos (48,36\% dos votos válidos). Mas esses números referem-se apenas aos votos válidos. Segundo outros dados apresentados pelo TSE, dos aproximadamente 143 milhões de eleitores aptos a votar, apenas 113 votaram, o que representa $21 \%$ de abstenção ${ }^{21}$. Como se não bastasse, dos 79\% que votaram, aproximadamente 2 milhões votaram em branco e 5 milhões anularam o voto. Isso significa que um valor aproximado de $30 \%$ dos eleitores não influenciou na escolha de seus representantes.

Como se isso já não fosse o bastante, as fragilidades dos arranjos institucionais entre os poderes, representado pelo presidencialismo de coalizão brasileiro, evidenciam a necessidade de construir alternativas que busquem espaços maiores e mais legítimos de democracia. Apenas para exemplificar, em 2015, depois de 27 anos da promulgação da Constituição Federal que institui um novo Estado Democrático de Direito, iniciou-se o processo de impeachment da Presidente Dilma Roussef, recém-eleita para o segundo mandato, acusada de ter descumprido a Lei de Responsabilidade Fiscal, ao ter editado decretos liberando crédito extraordinário. Assim, os frequentes processos de impeachment dos chefes dos executivos fazem aqueles que votaram desacreditar nesse sistema democrático, aumentando os índices de abstenção.

Então, não é difícil perceber os limites da simples representação. Mesmo aqueles que a defendem, como é o caso dos liberais, identificam seus riscos e por isso assumem uma percepção restritiva da própria democracia. Não é essa, porém, a posição defendida nesse trabalho. Aqui, acredita-se que a representação é importante e legítima, sem implicar, contudo, a defesa de sua exclusividade. Desta forma, a conjugação de diferentes maneiras de ouvir a sociedade e captar os interesses públicos precisam ser (re)pensadas e implementadas. Com esse intuito, a proposta apresentada se resume a criar caminhos de ouvir os movimentos sociais, que representam os mais variados interesses dos grupos e, por isso, a diversidade social. Agregar ao um modelo representativo de democracia tais ferramentas é uma forma de legitimar as escolhas e as decisões públicas.

\section{Os movimentos sociais muito além da simples representatividade}

21 Importante lembrar que, no Brasil, o voto é obrigatório para os brasileiros entre 18 e 70 anos de idade. 
A queda do muro de Berlim, em 1989, simbolizou o colapso dos regimes estabelecidos na Europa do Leste, o que levou a se imaginar que a democracia se estenderia amplamente a partir desse momento, especialmente com a participação ativa da cidadania na tomada de decisões políticas. Entretanto as coisas não ocorreram bem assim, e para Escudero Alday isso, provavelmente, decorreu de dois fatores: (a) a integração europeia ou latino-americana fez com que o cidadão fosse levado cada vez para mais longe do lugar onde se tomam as decisões que diretamente lhe afetam; assim, sua participação no processo de tomadas de decisão se tornou cada vez menor; (b) o processo de globalização da economia fez com que essa fugisse do controle dos Estados e, portanto, do jogo político em que são chamados a participar os cidadãos. ${ }^{22}$

Esses fatos fazem com que muitos setores da cidadania sintam certo rechaço com relação aos instrumentos tradicionais de participação, próprios da democracia representativa. Esse rechaço se traduz em descrédito da política e, consequentemente, na baixa participação eleitoral. O que se está demandando é mais e melhor democracia. Arguem o modelo tradicional de democracia representativa porque: (a) limita a participação em votar a cada 4 ou 5 anos; (b) suas instituições estão afastadas da cidadania e dos seus interesses; (c) seus poderes são estabelecidos por meio de um sistema de partidos, com pouca democracia interna, cada vez com menos debates e mais mídia; (d) produz políticos profissionais; e (e) em vez de cidadãos, o sistema gera consumidores e súditos. ${ }^{23}$

Tudo isso, acrescido a uma maior capacidade intelectual dos cidadãos conseguida por meio da universalização do sistema público de educação, pelas novas tecnologias de informação e pelo maior contato com outros Estados -, contribui para que, atualmente, o olhar do cidadão seja dirigido para a sociedade civil, isto é, para as associações, os movimentos sociais, os foros de cidadania, as cooperativas ou as ONGs, como espaços a partir dos quais se pode pressionar politicamente para se alcançar melhorias econômicas, sociais ou jurídicas.

A consequência é o surgimento de novos movimentos sociais: a articulação

22 ESCUDERO ALDAY, Rafael. Activismo y sociedad civil: los nuevos sujetos políticos. In: Lecturas de la sociedad civil. Um mapa contemporáneo de sus teorías. Edición de J. María Sauca y María I. Vences. Madrid: Trotta. 2007

23 FERNÁNDEZ, Ernesto Ganuza y SOTOMAYOR, Carlos Álvarez. Democracia y presupuestos participativos.

Barcelona: Icária, 2008. 
em outras formas de fazer política por meio de canais e instrumentos diferentes daqueles tradicionalmente oferecidos pelos partidos políticos. Confirma esta tese a ampla proliferação de associações, movimentos sociais, foros de participação e protesto, assembleias cidadãs e tantas outras. Essas entidades não se constituem em um fenômeno novo, mas é sim novidade a vocação com que atuam que é a de converter-se em sujeitos políticos; pretendem influenciar na tomada de decisões que afetam a coletividade e fazê-lo por meio de canais de participação política distintos dos modelos tradicionalmente institucionalizados. Em resumo, buscam mais e melhores formas de participação cidadã, diferentes das típicas da democracia representativa. Pretendem situar a sociedade civil - os movimentos sociais, cívicos e os cidadãos que os integram - no centro da discussão política.

As práticas associativas e os movimentos populares, de caráter espontâneo e autônomo, ganham impulso a partir dos anos 70, ensina Wolkmer ${ }^{24}$, articulandose em torno de interesses imediatos referentes às condições de vida e moradia, desvinculadas de instituições do Estado e de partidos oficiais. Tratava-se de alternativas que partiam da sociedade civil, independentemente dos parâmetros institucionais oferecidos pelos canais de representação tradicional. Isso representou a ruptura com toda a herança política, como produto de um espectro elitista, antipopular, autoritário e corporativista. Como destaca Offe ${ }^{25}$, abrem-se outras formas de ação dos movimentos sociais.

Os novos movimentos sociais vêm representar um paradigma alternativo de cultura política, na medida em que rompem com as antigas formas de organização e representação da sociedade (classes sociais, partidos políticos, sindicatos). $\mathrm{Na}$ atuação dos novos atores coletivos há que se "pensar na sociedade e na política já não como objetivação das estruturas ou da ação social do Estado, mas como um cenário criado e recriado por práticas de sujeitos em conflito". A distinção é clara, enquanto os antigos movimentos projetavam intentos essencialmente materiais, relações instrumentais, orientações para com o Estado e a organização vertical, os novos movimentos sociais buscam conduzir-se por critérios de efetividade, relações de expressividade, orientações comunitárias e organização horizontal26.

24 WOLKMER, Antonio Carlos. Pluralismo Jurídico. Fundamentos de una nueva cultura del derecho. Trad. David Sánchez Rubio. Sevilla: MAD, 2006.

25 OFFE, Claus. Partidos políticos y nuevos movimientos sociales. Madrid: Editorial Sistema, 1988.

26 LACLAU, Ernesto. Os novos movimentos sociais e a pluralidade do social. In: Revista Brasileira de Ciências 
Evidentemente que, como lembra Offe, os movimentos sociais, como paradigmas de uma nova cultura político-jurídica, devem passar necessariamente por la apreciación de varios requisitos, tales como contenido, valores, formas de acción y actores sociales ${ }^{27}$.

Para Scherer-Warren ${ }^{28}$, a diferença entre os velhos e os novos movimentos sociais está em sua forma de organização e no encaminhamento das lutas. Os primeiros incorporavam formas clientelistas e paternalistas de fazer política, eventualmente utilizavam-se da democracia representativa e não excluíam o recurso da violência. Os novos movimentos valorizam a participação ampliada das bases, a democracia direta sempre que possível e opõem-se, ao menos no plano ideológico, à centralização do poder e ao uso da violência. Quanto ao conteúdo dessas lutas, ambos apresentam demandas específicas e, por vezes, defendem transformações sociais mais gerais. O que há de inovador nos novos movimentos é a luta pela ampliação do espaço da cidadania, o que conduz, necessariamente, à modificação das relações sociais.

A base social desses novos movimentos sociais é identificada por Offe ${ }^{29}$ como uma nova classe média. Uma classe média cujas exigências carecem, em grande parte, da tipicidade da classe, já que suas metas são dispersas e universalistas, como as pretensões que atingem o pacifismo, a proteção do meio ambiente e a defesa dos direitos humanos. A nova classe média compõe alianças estáveis com outros elementos sociais, como os grupos periféricos e setores da antiga classe média. Tais movimentos de massas organizados que emergem frente à fragilidade e à inoperância das instituições oficiais buscam defender a subsistência e a identidade de seus membros, promovendo a mobilização contra a exploração, a opressão e a exclusão.

Então, quando um grupo de pessoas, convencidas de que nem os governos, nem o Estado, nem os partidos políticos ou grupos de interesses estabelecidos abordam corretamente suas reivindicações, organizam uma ação coletiva e suscitam a adesão de um grupo numeroso de ativistas para atrair a atenção dos 
Novos Estudos Jurídicos

poderes públicos. A este grupo se denomina movimento social, que se incorpora à sociedade.

Assim, tem-se a sociedade civil como o lugar do qual se pode alavancar uma radical mudança política, como um espaço de política ativa, transformadora da realidade. Esta concepção se apoia na tradição teórica de Gramsci. Advoga esse cientista político que a sociedade civil é uma plataforma para a conquista do poder político, trata-se de um mecanismo para transformar o Estado, para mudar todas suas estruturas de poder e dominação.$^{30}$

\title{
Como ensina Rezende ${ }^{31}$,
}

\begin{abstract}
Os movimentos sociais não podem ser pensados, apenas como meros resultados da luta por melhores condições de vida, produzidos pela necessidade de aumentar o consumo coletivo de bens e serviços. Os movimentos sociais devem ser vistos, também (e neles, é claro, os seus agentes), como produtores da História, como forças instituintes que, além de questionar o Estado autoritário e capitalista, questionam, com sua prática, a própria centralização/burocratização tão presentes nos partidos políticos.
\end{abstract}

Por evidente, nem todas as mobilizações sociais podem ser denominadas de movimento social. Os episódios de protestos pontuais, de reivindicações efêmeras, mesmo intensos, não se caracterizam como movimentos sociais, devido à ausência de conexões pessoais ou organizativas que garantam uma mínima continuidade no tempo. Gallardo ${ }^{32}$ distingue em três grandes formas os movimentos populares: (1) as explosões sociais - reúnem diversos setores populares (desempregados, funcionários públicos e privados, estudantes, grupos religiosos...) que podem gerar crises de governabilidade, trata-se de um levante com baixo nível de organização e não ideológico; (2) as mobilizações sociais também reúnem diversos setores populares. Seu nível de organização, a busca de objetivos precisos e uma condução ideológica são os fatores que as diferenciam das explosões sociais; (3) os movimentos sociais - que podem surgir de uma conjuntura específica, mas não se esgotam nela. Sua continuidade e acumulação

30 ESCUDERO ALDAY, Rafael. Activismo y sociedad civil: los nuevos sujetos políticos. In: Lecturas de la sociedad civil. Um mapa contemporáneo de sus teorías. Edición de J. María Sauca y María I. Vences. Madrid: Trotta. 2007

31 RESENDE, Antonio Paulo de M. Movimentos Sociais e Partidos Políticos: questões sobre lógica e estratégia política. In: Movimentos sociais: para além da dicotomia rural-urbano. João Pessoa. 1985.

GALLARDO, Helio. Siglo XXI. Producir un mundo. San José C.R.: Arlekin, 2006. 
de forças são dadas por suas raízes populares: a relação salarial ou a exploração da mão de obra, no caso do movimento de trabalhadores; a terra como valor cultural, familiar e econômico, no caso dos movimentos de pequenos agricultores e comunidades indígenas, as diversas discriminações de gênero como no caso do movimento feminista, a incompatibilidade entre a produção e a sustentabilidade do habitat como no movimento ecologista, etc.

Pode-se então definir um movimento social como uma rede interativa de indivíduos, grupos e organizações que, dirigindo suas demandas à sociedade civil e às autoridades, intervêm com relativa continuidade no processo de mudanças sociais, mediante o uso prevalecente de formas não convencionais de participação; ou, dito de outra maneira: trata-se de um conjunto de redes de interação informais entre uma pluralidade de indivíduos, grupos e organizações comprometidas com conflitos de natureza política ou cultural, sobre a base de uma específica identidade coletiva.

\section{CONSIDERAÇÕES FINAIS}

Diante da abordagem apresentada até aqui, é fácil perceber que os novos movimentos sociais fazem parte e se constituem em importantes atores no jogo político democrático. Sua incorporação na reivindicação de demandas tornou-se imprescindível para se alcançar objetivos concretos e determinados. A democracia representativa foi, sem dúvida, o elemento central na hora de consolidar os ideais liberais das revoluções burguesas, porém, no pós-Segunda Guerra, emergiu a necessidade de dividir esse protagonismo com outras formas de conjunção de interesses políticos e sociais. Nesse sentido, os movimentos sociais possuem ampla capacidade para generalizar demandas ou opiniões mediante diversos mecanismos de articulação e transmissão de ideias e propostas que surgem na contemporaneidade.

O espaço que a sociedade civil oferece encontra dificuldades para ser preenchido unicamente pelas formas tradicionais de democracia, como, por exemplos, o voto e os partidos políticos. Neste cenário, os movimentos sociais podem jogar um papel de protagonistas, fomentando um ativismo na sociedade 
civil, encaminhando a construção de uma cultura política e social contra hegemônica, estando, desta forma, comprometido com os valores da democracia participativa, a igualdade social e o desenvolvimento sustentável, apenas para citar alguns, frente ao capitalismo predatório, ao consumismo, ao individualismo e ao descrédito dos mecanismos coletivos.

As formas para desenvolver com êxito as demandas dos novos movimentos sociais são variadas, já que respondem a distintos interesses e se articulam sob diferentes fórmulas. Também são diversas suas formas de relação com o poder: uns se articulam como redes muito flexíveis; outros, não poderiam existir sem uma forte estrutura centralizada. Contudo, a característica comum desses grupos é sua forma particular de participação política que se destaca pela falta de vinculação orgânica com os tradicionais mecanismos de participação política, principalmente com os partidos políticos. Pretende, com isso, gerar hegemonia no âmbito em que atuam, de maneira que os cidadãos interessados ou afetados possam ver neles o referencial para a ação.

Enfim, em uma democracia, os movimentos sociais podem em muito contribuir para minimizar a falta de representatividade da sociedade civil decorrente da acentuada diversidade de interesses dos tempos atuais. Isso acaba redundando em benefício da própria democracia, que será reforçada por uma maior proximidade com as esferas nas quais se adotam as decisões que afetam os cidadãos. Trata-se de reforçar e incrementar o paradigma democrático.

\section{REFERÊNCIAS DAS FONTES CITADAS}

ALZAMORA, Manuel Menéndez. Participación y representación política. Valencia: Titant lo Blanch, 2009.

BRASIL, Tribunal Superior Eleitoral Disponível em:< http://www.tse.jus.br/ imprensa/noticias-tse/2014/Dezembro/plenario-do-tse-proclama-resultadodefinitivo-do-segundo-turno-da-eleicao-presidencial>. Acesso em: 22 maio 2018.

BELLAMY, Richard. Republicanism, democracy, and constitutionalism. In: C. Laborde and J. Maynor, eds., Blackwell, 2008, p. 159-189. Disponível em: < http:// 
papers.ssrn.com/sol3/papers.cfm?abstract_id=1520386>. Acessado em 11 jul. 2014.

BOBBIO, Norberto. O futuro da democracia. Tradução de Marco Aurélio Nogueira. 11 ed. São Paulo: Paz e Terra, 2000.

BOHMAN, James. O que é a deliberação pública? Uma abordagem dialógica. In: MARQUES, Ângela Cristina Salgueiro. A deliberação pública e suas dimensões sociais políticas e comunicativas: textos fundamentais. Belo Horizonte: Autêntica Editora, 2009, p. $31-84$.

CASQUETE, Jesús. Política, cultura y movimientos sociales. Bilbao: Bakeaz, 1998.

DOWBOR, Ladislau. Democracia econômica: alternativas de gestão social. Petrópolis: Vozes, 2008.

ESCUDERO ALDAY, Rafael. Activismo y sociedad civil: los nuevos sujetos políticos. In: Lecturas de la sociedad civil. Um mapa contemporáneo de sus teorías. Edición de J. María Sauca y María I. Vences. Madrid: Trotta. 2007

FERNÁNDEZ, Ernesto Ganuza y SOTOMAYOR, Carlos Álvarez. Democracia y presupuestos participativos. Barcelona: Icária, 2008.

GALLARDO, Helio. Siglo XXI. Producir un mundo. San José C.R.: Arlekin, 2006

GORCZEVSKI, Clovis, BELLOSO MARTIN, Nuria. A necessária revisão do conceito de cidadania [recurso eletrônico]: movimentos sociais e novos protagonistas na esfera pública democrática. Santa Cruz do Sul: EDUNISC, 2011.

IBARRA, Pedro y LETAMENDIA, Francisco. Los movimientos Sociales. In: BADIA, Miquel Camina. Manual de Ciencia Política. 3. ed. Madrid: Tecnos, 2008.

IBARRA, Pedro y LETAMENDIA, Francisco. Los movimientos Sociales. In: BADIA, Miquel Camina. Manual de Ciencia Política. 3. ed. Madrid: Tecnos, 2008.

IBARRA, Pedro y TEJERINA, Benjamin (editores). Los movimientos sociales. Transformaciones políticas y cambio cultural. Madrid: Trotta, 1998.

KNIGHT, Jack. Agregação e deliberação: sobre a possibilidade da legitimidade democrática. In: WERLE, Denilson Luis. MELO, Rúrion Soares. A democracia deliberativa. São Paulo: Editora Singular, Esfera Pública, 2007.

LACLAU, Ernesto. Os novos movimentos sociais e a pluralidade do social. In: Revista Brasileira de Ciências Sociais n² 2. São Paulo. 1986. 
LARAÑA, Enrique y GUSFIELD, Joseph (Editores). Los nuevos movimientos sociales. De la ideología a la identidad. Madrid: CIS, 1995.

MARDONES, José María (Editor). Diez palabras clave sobre movimientos sociales. Estella, Navarra: Verbo Divino, 1996.

MARTÍ, José Luis. La república deliberativa: una teoria de la democracia. Madrid: Marcial Pons, 2006.

MARTIN, Nuria Belloso. Movimientos sociales actuales: ¿emancipación o resistencia?. In: Direitos Fundamentais e Justiça. Porto Alegre: Revista do Programa de Pós-Graduação em Direito - Mestrado Doutorado, da Pontifícia Universidade Católica do Rio Grande do Sul. n 12, julho/setembro. 2010.

MARTINÉRZ, Antonia. Representación política y calidad de democracia. In: MARTINÉZ, Antoni (Coord). Representación y calidad de la democracia en España. Madrid: Tecnos, 2006.

MILL, John Stuart. Sobre la liberdad. Tradução de N. R. Salmones. Madrid: Alianza, 1986.

MOSCOVICI, Serge. La era de las multitudes. Un tratado histórico de la psicología de masas. México: FCE, 1985.

NADALES, Antonio Porras. El debate sobre la crisis de la representación. Madrid: Tecnos, 1996.

NOVAIS, Jorge Reis Novais. Direitos fundamentais: trunfos contra a maioria. Coimbra: Coimbra Editora, 2006.

OFFE, Claus. Partidos políticos y nuevos movimientos sociales. Madrid: Editorial Sistema, 1988.

OLSON, Mancur. The Logic of Collective Action: Public Goods and the Theory of Groups, Harvard University Press, 1st ed. 1965.

PASQUINO, Giuseppe. Movimenti sociali. In: BOBBIO, MATTEUCCI y PASQUINO (Coord). Dizionario di Politica. Milano: Ed. Tea, 1992.

PIÑAR MAÑAS, J. L. El tercer sector iberoamericano. Valencia: Tirant lo Blanch, 2001.

RESENDE, Antonio Paulo de M. Movimentos Sociais e Partidos Políticos: questões sobre lógica e estratégia política. In: Movimentos sociais: para além da 
dicotomia rural-urbano. João Pessoa. 1985.

ROCHER, G. Introducción a la sociología general. Barcelona: Ed. Herder, 1983.

RUBINSTEIN, Juan Carlos. Sociedad Civil y Participación Ciudadana. Madrid: Editorial Pablo Iglesias, 1994.

SANTOS, Boaventura de Sousa. El milenio huérfano. Ensayos para una nueva cultura política. Madrid: Trotta. 2005.

SCHERER-WARREN, Ilse. Movimentos sociais. Um ensaio de interpretação sociológica. $2^{\mathrm{a}}$ ed. rev. Florianópolis: Editora da UFSC, 1987.

SCHERER-WARREN. Ilse. Redes de Movimentos Sociais. 4. ed. São Paulo: Edições Loyola, 2009.

SCHUMPETER, Joseph A. Capitalismo, socialismo e democracia. Trad. por Ruy Jungmann. Rio de Janeiro: Editora Fundo de Cultura, 1961.

TARDE, Gabriel. A opinião e as massas. 2. ed. Tradução de Eduardo Brandão. São Paulo: Martins Fontes, 2005.

TEJERINA, Benjamín. Los movimientos sociales y la acción colectiva. De la producción simbólica al cambio de valores. In: IBARRA, Pedro y TEJERINA, Benjamin (editores). Los movimientos sociales. Transformaciones políticas y cambio cultural. Madrid: Trotta, 1998.

TOURAINE, Alain. Movimientos sociales de hoy. Actores y analistas. Barcelona: Ed. Hacer, 1990.

VALLESPÍN, Fernando. Sociedad civil y 'crisis de la política'. In: Isegoría, n 13, 1996

TOCQUEVILLE, Alexis. A democracia na América: lei e costumes. Tradução de Eduardo Brandão. 2a ed. São Paulo: Martins Fontes, 2005.

WOLKMER, Antonio Carlos. Pluralismo Jurídico. Fundamentos de una nueva cultura del derecho. Trad. David Sánchez Rubio. Sevilla: MAD, 2006.

Recebido em: junho/2018

Aprovado em: agosto/2018 